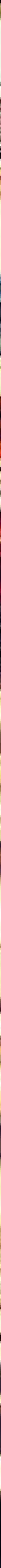


[VANESSA BEATRIZ BORTULUCCE]

Doutora em História Social pela Universidade Estadual de Campinas; docente do Centro Universitário Assunção

(UNIFAI), da Universidade São Judas Tadeu e do Museu de Arte Sacra de São Paulo.

\section{História de \\ uma cor: Verde}

Resenha de PASTOUREAU, Michel. Green: the history

of a color. New Jersey:

Princeton University Press, 2014, 240 p. Tradução: Jody

Gladding (edição inglesa) 
No início da segunda década do século anterior, dois historiadores franceses, Marc Bloch e Lucien Febvre, propuseram uma revisão da atividade do historiador, bem como novas reflexões acerca de seus objetos e suas metodologias. Essas considerações deram abertura ao que se chamou de Escola dos Annales, que ganhou fôlego com a adesão de estudiosos, como Fernand Braudel, Jacques Le Goff, Pierre Nora, e defendia a adoção de modos diferentes de pensar e escrever a história, sugerindo "novos problemas, novos objetos e novas abordagens", mote da terceira geração da Escola. Fato é que o decorrer do tempo somente ampliou as questões levantadas desde 1923, com a primeira geração do grupo, estendendo-se até os dias de hoje, quando é muito improvável não encontrar um pesquisador que não tenha sido influenciado pela teoria da história dos Annales.

0 livro Green: the history of a color (2014) é uma daquelas obras que atestam de modo contundente o quanto aqueles historiadores franceses foram determinantes nos estudos realizados pelos pesquisadores mais recentes. Encontrar um livro que se dedica ao estudo de uma cor, entendida como um objeto de análise, capaz de ser compreendida historicamente, é colocar-se diante de exemplos admiráveis que atestam quanto o ofício do historiador é amplo e complexo, e também como os novos objetos apresentam-se inesgotáveis ao pesquisador.

A pesquisa de Michel Pastoureau é um desses trabalhos marcantes na esteira do movimento dos Annales, com uma proposta interdisciplinar que procura compreender a história humana sob outras perspectivas, utilizando a micro-história, a história das mentalidades, a história da arte, a sociologia, a antropologia, a ciência. Pastoureau é autor de Bleu (2000) e Rouge (2016), ambos traduzidos para o inglês, e atualmente finaliza o volume sobre a cor amarela - os livros integram uma série na qual cada volume é dedicado a uma cor específica. Além desses, escreveu Preto: história de uma cor, a única obra de toda a coletânea publicada em língua portuguesa em nosso pais, pela Editora Senac em conjunto com a Imprensa Oficial (2011). Essa série de livros vem preencher uma lacuna nos estudos dos pesquisadores das mais diversas áreas das Ciências Humanas. Acreditamos que todo pesquisador envolvido com os estudos culturais, em seus mais diversos aspectos, deve conhecer o trabalho do pesquisador parisiense nascido em 1947.

Historiador, professor de História Medieval, diretor de pesquisa na École Pratique des Hautes Études de la Sorbonne, em Paris, Michel Pastoureau é es- 
pecialista em história das cores, simbologia e heráldica, com diversas publicações sobre esses temas. Green: the history of a color é uma obra que confirma o profundo domínio do autor acerca desse universo de estudo, um livro que surpreende o leitor não apenas ao atestar a sua erudição - expressa em um texto fluido, límpido, sem prolixidades, acessivel a todos os leitores -, mas, principalmente, na medida em que percorremos a história do seu objeto de estudo, a cor verde. Farto em ilustrações, o texto divide-se em cinco seções, cada uma delas ressaltando uma caracteristica da cor que predominou em cada tempo histórico: "Incerta" (da Antiguidade até o ano 1000), "Cortesã" (Idade Média), "Perigosa" (Era Moderna), "Secundária" (fins da Era Moderna e início da Era Contemporânea), "Calmante" (da Modernidade aos dias de hoje). A obra também conta com uma notável introdução, obrigatória para todos aqueles que trabalham com imagens. Nela, Pastoureau realiza um salutar exercício metodológico, orientando o leitor acerca dos desafios e armadilhas à espreita quando se pretende escrever a história de uma cor. As observações estão divididas em três grupos: o primeiro diz respeito às diferentes temporalidades. As cores chegam até nós não em seus aspectos originais, mas sim transformadas pelo passar dos anos, décadas, séculos. 0 que vemos é a cor que se apresenta com os vernizes do tempo: desbotada, escurecida, manchada; vemos as cores, lembra-nos Pastoureau, em condições de iluminação muito diferentes das que ocorriam nas sociedades anteriores à nossa. Questões essas, provoca o autor, que às vezes nem mesmo os pesquisadores se dão conta ao visitar museus, por exemplo. 0 segundo aspecto destacado por Pastoureau diz respeito à metodologia propriamente dita. 0 pesquisador, ao estudar as cores, tem, diante de si, ao mesmo tempo desafios e dificuldades de toda ordem: materiais, técnicas, iconográficas, ideológicas, históricas, simbólicas. 0 autor afirma que um estudo profícuo das cores só pode ser empreendido munido de uma disposição interdisciplinar por parte dos pesquisadores, e quando um deles tende a descartar alguns desses aspectos apresentados acima, desconhecendo a igual importância de cada um deles no âmbito da pesquisa, o produto final apresenta-se sem substância.

0 terceiro desafio ao estudar as cores é de ordem epistemológica: as definições, classificações e concepções sobre as cores que possuímos hoje não podem ser projetadas, de modo algum, no passado. 0 desafio da nomenclatu$\mathrm{ra}$, as problemáticas específicas do estudo da linguagem oral e escrita, muitas delas imersas em caloroso debate, tornam o fazer da história da cor, segundo o francês, um terreno no qual deve-se pisar com cuidado.

As recompensas para quem persiste nesse intento, no entanto, são várias. Estamos diante de um livro que desvela toda uma sociedade a partir de um objeto novo: a cor verde, que, pasme, descobrimos ao longo da leitura, foi na maior parte do tempo odiada pela maioria das pessoas. É dificil compreender essa afirmação, já que atualmente o verde está associado, em grande parte das vezes, a aspectos positivos: é a cor da ecologia, da vida sustentável, da preservação da natureza, dos grupos ambientais, das atitudes conscientes em relação ao nosso entorno; é a cor do detox, da limpeza, das férias no campo, da saúde, do esporte. É a cor da esperança; não à toa, a Pantone escolheu, 
dentro de sua cartela de cores para o ano de 2017, o tom Greenery, representante de uma intenção e uma expectativa de que os próximos dias sejam menos turbulentos do que aqueles de 2016 (https://www.pantone.com/color-of-the-year-2017).

Pastoureau estuda a cor verde de modo cronológico: começa com um afresco de Pompeia e termina na pós-modernidade; nesse trajeto, combina habilmente os aspectos materiais e imateriais da cultura ocidental no sentido de verificar o máximo da presença do verde na sociedade e nas interações entre os indivíduos. Detendo-se em suportes como o vestuário, o mobiliário, a heráldica, a arte religiosa, passando pelos papéis de parede e pelas caricaturas de marcianos nos jornais, Pastoureau nos direciona para aspectos que muitas vezes não levamos em consideração, ou até mesmo para outros que não damos a atenção devida. Seu texto é um retomar da história da humanidade, uma original revisitação das práticas e dos valores do homem, e da importância das cores nesse processo. 0 autor não apresenta nenhum preconceito em relação às fontes analisadas: passeia com desenvoltura desde uma tela de Van Eyck até uma charge de revista. A sua postura e o seu respeito diante de seu objeto e das produções culturais do homem, sem restrições, é que fazem de sua obra imperativa para os pesquisadores e o público em geral.

Ao longo do texto, o autor constrói habilmente uma trajetória da cor em pauta, demorando-se nas questões mais nebulosas, recobertas de incertezas. 234 ] Assim, descobrimos que a menção ao nome verde é quase inexistente nos textos gregos antigos, tornando rara a aparição da nomenclatura da cor nos textos mais clássicos, inclusive nos de Homero. Contudo, o mérito maior de Pastoureau é manter-se alerta o tempo todo contra falácias e armadilhas teóricas e investigativas, algumas irresistiveis ao leitor desatento; assim, 0 autor, sobre essa questão, imediatamente nos adverte: "Não nomear uma cor não significa que a mesma não possa ser vista" (p. 19). Algo que pode parecer óbvio, mas assim o é somente depois que entramos em contato com a lucidez teórica de Pastoureau, que nos conduz cuidadosamente em terrenos pouco seguros e facilmente abertos a interpretações errôneas e simplistas.

Cor presente desde sempre na vida dos homens, por ser por excelência a cor da natureza, o verde era celebrado pelos egipcios antigos, pois era o tom da vida, da fertilidade, de Osíris. Na Europa, porém, conheceu destino menos feliz: o verde, afirma Pastoureau, não recebeu boas avaliações ao longo da história. Poucos indivíduos realmente o apreciavam por sua beleza - 0 imperador romano Nero era um deles, fascinado por esmeraldas; para a grande maioria, porém, o verde era tido como uma cor desonesta, instável. A preparação do pigmento era extremamente complexa e tóxica: a prática mais usual era mergulhar barras de cobre em vinagre para que se pudesse extrair, então, a oxidação de pigmento esverdeado; a maioria dos tons de verde era tóxica, desbotava muito rapidamente, e alguns processos de pigmentação podiam envenenar as pessoas a longo prazo, fosse pelo contato da pele com o tecido tingido, ou, mais tarde, no século XIX, pelo papel de parede com estampas nessa cor, responsável por reações químicas silenciosamente mortíferas (nesse último caso, 
a vitima mais célebre foi Napoleão Bonaparte: sua habitação em Santa Helena era recoberta de um papel de parede com estampas esverdeadas; mais tarde, descobriu-se que a umidade do ambiente propiciava a evaporação do arsênico presente nos pigmentos, ocasionando envenenamento).

0 verde, uma cor que desbotava facilmente, atestava uma moral não confiável, volúvel, traiçoeira: é por isso que se tornou, junto com a cor amarela, a coloração mais frequente dos trajes de Judas nas pinturas e nos afrescos da arte cristã. É a partir desses exemplos que Pastoureau oferece um relevante contributo, demonstrando que os aspectos fisicos, materiais e técnicos da produção de uma cor são dados contribuintes na formação dos simbolismos, na constituição de uma moral cromática. Assim, ironicamente, delineia-se a má sorte - apesar de ser a cor do trevo de quatro folhas - do verde: mesmo sendo a cor da deusa Fortuna (o que explica o motivo pelo qual as toalhas de mesas de jogos de cartas são dessa cor), mesmo passando a representar o dinheiro e a abundância material, o verde será visto como negativo por muitos séculos: é a cor dos povos germânicos, bárbaros, incivilizados; é a cor da unificação do Islã, o que ocasionou a antipatia da Igreja; é a cor dos seres sobrenaturais, dos dragões, serpentes, crocodilos e sapos, das poções das bruxas, do diabo, da pele enfermiça; é a cor de mau agouro no teatro francês de Molière; é rejeitado por Kandinsky, que a considerava uma cor estática e passiva, como uma "vaca ruminante". Ainda assim, é ao mesmo tempo a cor da primavera para o Ocidente medieval - época do renascimento da natureza e, consequentemen235 te, do amor, pois, no medievo, os afetos se tornam propícios em tempos primaveris. E o amor beneficia sobretudo os jovens - o verde é, pois, também a cor da juventude. Goethe é fascinado pelo verde; é a cor das fadas, dos românticos (dividindo espaço com o preto), dos botânicos. Assim, Pastoureau observa, a cultura do Ocidente aos poucos criou a cultura do bom verde e do mau verde. Dessa forma, não é de espantar que, em relação a essa cor tão dúbia, tão inconstante, pensa-se, deve-se tomar cuidado. Cor do jardim, pacifica, e ao mesmo tempo das fardas dos soldados, em um esverdeado ameaçadoramente bélico: como confiar no verde?

É nessa complexidade fascinante que se edifica a história do verde, e o exaustivo trabalho de Pastoureau transforma e enriquece nossa compreensão acerca das cores, bem como o significado histórico e social delas. Tida atualmente como favorita somente por $15 \%$ da população europeia, conforme pesquisa apresentada no livro, o verde consolidou, apesar disso, sua posição de importância na sociedade contemporânea: tornou-se a cor da saúde, da liberdade, da esperança. Nas palavras do autor, tornou-se uma cor "messiânica, que irá salvar o mundo" (p. 221). 